Sharif University of Technology
Scientia Iranica
SCIENTIA
IRANICA
http://scientiairanica.sharif.edu

\title{
Effect of non-Darcy flow on induced stresses around a wellbore in an anisotropic in-situ stress field
}

\author{
A. Tohidi ${ }^{\mathrm{a}}$, A. Fahimifar ${ }^{\mathrm{a}, *}$, and V. Rasouli ${ }^{\mathrm{b}}$ \\ a. Department of Civil and Environmental Engineering, Amirkabir University of Technology, Tehran, Iran. \\ b. Department of Petroleum Engineering, University of North Dakota, Grand Forks, ND, USA. \\ Received 28 January 2017; received in revised form 29 July 2017; accepted 2 December 2017
}

\section{KEYWORDS \\ Non-Darcy flow; \\ Wellbore induced \\ stresses; \\ Analytical solution; \\ Numerical models; \\ Sensitivity analysis.}

\begin{abstract}
After drilling a well, the stresses will be altered and the induced stresses present the new state of stress. These induced stresses result in geomechanical problems. Studies have indicated that the flow of hydrocarbon into the wellbore influences the induced stresses. Darcy equation has been used in the past; however, the laminar flow assumption embedded in this equation cannot correctly model the flow of fluid when a non-Darcy flow dominates near a wellbore. Examples of such situations include the gas wells. In this study, analytical equations were developed based on Forchheimer flow equation to incorporate the effect of non-Darcy flow on the induced stresses around a wellbore. Then, the simplified solutions were presented by considering the second term of Forchheimer flow equation. It was found that the difference between the results of Darcy and non-Darcy flow models was proportional to the drawdown pressure. Further studies included numerical simulation of non-Darcy fluid flow in a typical reservoir. Comparison of the results with the analytical models indicated that the magnitude of stresses in non-Darcy flow was larger than that in Darcy flow. Finally, sensitivity of the reservoir properties to the induced stresses in the non-Darcy flow regime was investigated.
\end{abstract}

(C) 2019 Sharif University of Technology. All rights reserved.

\section{Introduction}

Drilling operation leads to redistribution of stresses around a well. The redistributed stresses, known as induced stresses, are tangential, radial, and vertical. As the wellbore wall is a principal stress plane, it is most severely affected by the presence of induced stresses as a result of drilling operation. This will result in different incidences, with wellbore instability and sand production being only two examples of the many. The financial loss resulting from these incidences is significant and reported to be over six billion dollars

*. Corresponding author.

E-mail address: fahim@aut.ac.ir (A. Fahimifar)

doi: $10.24200 /$ sci. 2017.4603 in the case of wellbore instability [1] and tens of billion dollars due to sand production [2], annually.

Estimation of drilling induced stresses is fundamental to several applications in oil and gas industries. These stresses are the input to wellbore stability analysis, sanding prediction, hydraulic fracturing design, and determining the optimum completion [3-5].

The impact of the flow of hydrocarbon when it enters the wellbore on the induced stresses around the wellbore has been reported by researchers [6-9]. For example, the tangential stresses are increased due to stress concentration and fluid withdrawal, which leads to compressive failure around a cavity of a well [6]; or when the pore pressure gradient is very high, the effective radial stress may be tensile [8].

While the assumption of laminar flow near wellbore for oil reservoirs may be justified, this will lead 
to a significant error when applied to gas wells, where turbulent flow near wellbore is dominant [10,11]. This implies that Darcy flow calculations cannot be used to modify the induced stresses around the wellbore in case of a gas well. This applies not only to wells producing gas, but also to the wells where the gas is injected for Enhanced Oil Recovery (EOR) or storage purposes. The non-Darcy fluid flow also exists in hydraulically fractured formations $[12,13]$. In petroleum engineering, the effect of non-Darcy flow on well performance has been studied widely and the concept of skin effect has been introduced to determine the pressure drop [14-16]. This is while most of the current solutions to the estimation of the stress around the wellbore are based on Darcy flow, i.e., laminar flow assumption near wellbore $[3,7,14,17]$. There are only few studies that assume non-Darcy flow to develop sand production model for high-rate gas wells [6], or derive modified equations for non-Darcy effect on isotropic stress field [9].

This indicates the need for developing solutions which include the non-Darcy flow to correctly model the turbulent flow near wellbore in case of, e.g., gas production or injection. This paper expands the application of the Forchheimer equation to non-Darcy flow. Numerical simulations are also conducted to support the applicability of the developed models.

\section{Coupling fluid flow to induced stresses}

Kirsch's equations are perhaps the most commonly used analytical solutions to estimate the stresses induced around a wellbore. Kirsch (1898) derived these equations for a circular hole in an infinite solid medium under uniform loads applied far from the hole [18]. Kirsch's solution is based on assumptions such as two-dimensionality, elasticity, and non-porous medium. Further studies by Bradley [19] based on Fairhurst's work [20] included the effect of mud pressure on calculating the drilling induced stresses. In this work, however, plane strain condition and omission of the flow of fluid near wellbore and its impact on induced stresses were the two major assumptions. In 1986, Santarelli et al. developed a nonlinear elastic relationship based on their studies on shale formations and concluded that maximum stress could take place near the wellbore, not at the wellbore wall. Yet, this model also ignored the near-wellbore fluid flow [21].

The poroelastic theory proposed by Yew and Liu (1992) addressed the issue of flow and deformation coupling in porous media [22]. They introduced poroelasticity theory in order to study the effects of fluid flow on wellbore stability, because this flow induced additional normal stresses. Bradford and Cook (1994) developed a semi-analytical elastoplastic model [19]. This model applies to vertical wells subjected to isotropic in-situ stress and pore pressure fields, and predicts the onset of sanding. Chen et al. (2003) developed a model that included the poroelastic, chemical, and thermal effects [17]. Han and Dusseault (2003) derived the effective stress distributions around a wellbore producing oil with poro-inelastic and different boundary conditions [7]. All of the above models are based on Darcy's fluid flow assumption.

As stated earlier, only a few studies have considered the effect of non-Darcy flow on rock mechanics applications in particular stress estimations. Wang et al. (1991) studied the effect of non-Darcy flow on the stability of perforation of gas wells using elastoplastic theory. They concluded that non-Darcy flow would significantly increase the instability of perforation tunnels [24]. Ong et al. (2000) combined equilibrium equations with the Mohr-Coulomb failure criterion and non-Darcy fluid flow to study the onset of sanding in spherical or cylindrical perforation of high-rate gas wells. They inferred from the results for the specific reservoir that the non-Darcy flow reduced the critical drawdown pressure by half as compared to the Darcy case [6]. They also proposed a method for predicting the onset of formation solid production [25].

In this study, based on the poroelastic theory, the effect of fluid flow (Darcy/non-Darcy) on induced stresses near the wellbore is investigated.

\section{Developed analytical model}

Forchheimer (1901) established differential equation (1) to estimate the flowing pressure near wellbore as a function of wellbore radius [26]:

$$
\frac{d P_{f}}{d r}=\frac{\mu}{k} \frac{Q_{0}}{2 \pi r h}+\beta \rho \frac{Q_{0}^{2}}{4 \pi^{2} h^{2} r^{2}} .
$$

The first term in this equation is the Darcy flow with laminar flow assumption. The second term accounts for turbulent flow where the non-Darcy coefficient, $\beta$, is determined empirically as a function of absolute permeability. In Eq. (1), $\mu, Q_{0}, k, \rho, h$, and $r$ are viscosity, flow rate, permeability, fluid density, thickness of production layer, and distance from the wellbore, respectively.

After solving differential Eq. (1), the boundary conditions need to be applied to make the results converge near wellbore fluid flow, which is the objective of this study. Here, the boundary conditions are established as:

$$
\begin{aligned}
& P_{f_{\left(r=R_{w}\right)}}=P_{w}, \\
& P_{f_{\left(r=R_{0}\right)}}=P_{f 0},
\end{aligned}
$$

that is, the fluid pressure at the wellbore wall is $P_{w}$ and it becomes equal to the reservoir pressure, $P_{f 0}$, at a large distance from the wellbore wall $\left(r=R_{0}\right)$. 
Applying boundary conditions of Eqs. (2) and (3) to Eq. (1) will lead to Eq. (4):

$$
\begin{gathered}
P_{f(\text { Forchheimer flow })}=a \ln \left(\frac{r}{R_{0}}\right)+b\left(\frac{1}{R_{0}}-\frac{1}{r}\right)+P_{f 0} \\
=a \ln \left(\frac{r}{R_{w}}\right)+b\left(\frac{1}{R_{w}}-\frac{1}{r}\right)+P_{w} .
\end{gathered}
$$

In Eq. (4), coefficients $a$ and $b$ are defined as:

$$
\begin{aligned}
& a=\frac{P_{0}-P_{w}}{\ln \left(\frac{R_{0}}{R_{w}}\right)}-\frac{b\left(R_{0}-R_{w}\right)}{R_{0} \cdot R_{w} \cdot \ln \left(\frac{R_{0}}{R_{w}}\right)}, \\
& b=\frac{\beta \rho Q_{0}^{2}}{4 \pi^{2} h^{2}} .
\end{aligned}
$$

In order to determine the near-wellbore induced stresses, we adopt the equations for a homogenous medium subjected to anisotropic horizontal stresses. These equations are presented as Eq. (A.1) in Appendix A [3].

Coupling Eqs. (A.1) and (4) together will result in Eqs. (7) to (9), as shown in Box I, which allow for the estimation of drilling induced radial, tangential, and vertical stresses around a wellbore drilled in a homogenous formation subjected to anisotropic horizontal stresses. These equations are based on the assumption that Forchheimer Eq. (4) represents the fluid flow near wellbore.

Coefficients $a_{1}$ and $a_{2}$ are defined as Eq (A.2) in Appendix A. It is noteworthy that the non-Darcy parameter, $\beta$, is embedded in parameter $b$ in Eq. (6). Determining parameter $\beta$ is not straight forward and several experimental correlations have been proposed to estimate this parameter [10].

In the next section, we discuss how parameter

$$
\begin{aligned}
& \sigma_{r(\text { Forcheimer flow })}=a_{1}\left(1-\frac{R_{w}^{2}}{r^{2}}\right)+a_{2}\left(1+3 \frac{R_{w}^{4}}{r^{4}}-4 \frac{R_{w}^{2}}{r^{2}}\right) \cos 2 \theta+\tau_{x y}^{\circ}\left(1+3 \frac{R_{w}^{4}}{r^{4}}-4 \frac{R_{w}^{2}}{r^{2}}\right) \sin 2 \theta \\
& +2 \frac{\eta}{r^{2}}\left\{\frac{\left(-R_{w}{ }^{2}+r^{2}\right)\left[\left(\frac{R_{0}}{2}(0.5 a+b)\right)+\frac{a \cdot R_{w}^{2}\left(\ln \left(\frac{R_{w}}{R_{0}}\right)-0.5\right)}{2 R_{0}}+b\left(\frac{R_{w}^{2}}{2 R_{0}}-R_{w}\right)\right]}{R_{0}{ }^{2}-R_{w}{ }^{2}}\right. \\
& \left.+\frac{a\left(\left(r^{2} \ln \left(\frac{r}{R_{0}}\right)-0.5 r^{2}-R_{w}^{2} \ln \left(\left(\frac{R_{w}}{R_{0}}\right)+0.5 R_{w}^{2}\right)\right.\right.}{2 R_{0}}+b\left(\frac{-R_{w}{ }^{2}+r^{2}}{2 R_{0}}+R_{w}-r\right)\right\}+P_{w} \frac{R_{w}^{2}}{r^{2}}
\end{aligned}
$$

$\sigma_{\theta(\text { Forcheimer flow })}=a_{1}\left(1+\frac{R_{w}^{2}}{r^{2}}\right)$

$$
\begin{aligned}
& -a_{2}\left(1+3 \frac{R_{w}^{4}}{r^{4}}\right) \cos 2 \theta-\tau_{x y}^{\circ}\left(1+3 \frac{R_{w}^{4}}{r^{4}}\right) \sin 2 \theta-2 \frac{\eta}{r^{2}}\left\{+\frac{1}{2} \frac{a\left(r^{2} \ln \left(\frac{r}{R_{0}}\right)\right)-0.5 r^{2}-R_{w}^{2} \ln \left(\frac{R_{w}}{R_{0}}\right)+0.5 R_{w}^{2}}{R_{0}}\right. \\
& +\frac{1}{2} \frac{b\left(2 R_{0} R_{w}-2 R_{0} r-R_{w}^{2}+r^{2}\right)}{R_{0}}-\frac{\left(R_{w}^{2}+r^{2}\right)}{R_{0}^{2}-R_{w}^{2}} \times\left[\frac{1}{4} R_{0}(a+2 b)+\frac{1}{2} \frac{a R_{w}^{2}\left(\ln \left(\frac{R_{w}}{R_{0}}\right)-0.5\right)}{R_{0}}\right. \\
& \left.\left.-\frac{1}{2} \frac{b R_{w}\left(-R_{w}+2 R_{0}\right)}{R_{0}}\right]-a r^{2} \ln \left(\frac{r}{R_{0}}\right)-\frac{b r\left(R_{0}-r\right)}{R_{0}}\right\}-P_{w} \frac{R_{w}^{2}}{r^{2}}
\end{aligned}
$$

$\sigma_{z \text { (Forcheimer flow })}=\sigma_{z}^{\circ}-4 v\left(a_{2} \times \frac{R_{w}^{2}}{r^{2}} \times \cos 2 \theta+\tau_{x y}^{\circ} \times \frac{R_{w}^{2}}{r^{2}} \times \sin 2 \theta\right)+2 \eta\left(a \ln \left(\frac{r}{R_{0}}\right)+b\left(\frac{1}{R_{0}}-\frac{1}{r}\right)\right)$

$$
-\frac{4 \eta v\left(\frac{1}{2} R_{0}\left(\frac{1}{2} a+b\right)+\frac{1}{2} \frac{a R_{w}^{2}\left(\ln \left(\frac{R_{w}}{R_{0}}\right)-\frac{1}{2}\right)}{R_{0}}+b\left(\frac{1}{2} \frac{R_{w}^{2}}{R_{0}}-R_{w}\right)\right)}{R_{0}^{2}-R_{w}^{2}}
$$


$\beta$ considering the second term of Eq. (4) for the specific case of fluid flow in high-permeability gas wells $[27]$.

\section{Induced stresses around a gas well}

Here, Eqs. (7) to (9) are used to estimate the drilling induced stresses in the general from where turbulent flow is dominant. The previous research studies have indicated that the flow rate in gas wells is proportional to the square root of the hydraulic gradient [27]. Therefore, the second term of the Forchheimer equation (Eq. (1)) is used to present the fluid flow in gas wells.

By solving the second term of the differential equation (1) and applying the boundary conditions (Eqs. (2) and (3)), the pore pressure distribution as a function of radius from the well is defined as Eq. (10):

$$
\begin{aligned}
P_{f(\text { Gas flow })} & =\frac{\left(P_{f 0}-P_{w}\right) R_{0}}{\left(R_{0}-R_{w}\right)}\left(-\frac{R_{w}}{r}+1\right)+P_{w} \\
& =\frac{\left(P_{f 0}-P_{w}\right) R_{w}}{\left(R_{0}-R_{w}\right)}\left(-\frac{R_{0}}{r}+1\right)+P_{f 0} .
\end{aligned}
$$

Eq. (10) only requires pressure and radius parameters and, contrary to Eq. (4), it does not include parameter $\beta$ to calculate the pore pressure. On the other hand, applying the boundary conditions implies that Eq. (11) is valid:

$$
\frac{\left(P_{f 0}-P_{w}\right) R_{0} R_{w}}{\left(R_{0}-R_{w}\right)}=\frac{\beta \rho Q_{0}^{2}}{4 \pi^{2} h^{2}} .
$$

Thus, the left side of Eq. (11) was used instead of its right side in Eq. (10).

In order to develop the stress equations coupled to the non-Darcy flow equation, we substitute Eq. (10) into Eq. (A.1). This results in Eqs. (12) to (14):

$$
\begin{aligned}
& \sigma_{\mathrm{r}(\text { Gas flow })}=a_{1}\left(1-\frac{R_{w}^{2}}{r^{2}}\right) \\
& +a_{2}\left(1+3 \frac{R_{w}^{4}}{r^{4}}-4 \frac{R_{w}^{2}}{r^{2}}\right) \cos 2 \theta \\
& +\tau_{x y}^{\circ}\left(1+3 \frac{R_{w}^{4}}{r^{4}}-4 \frac{R_{w}^{2}}{r^{2}}\right) \sin 2 \theta \\
& +2 \frac{\eta}{r^{2}}\left(P_{f_{0}}-P_{w}\right)\left(\frac{R_{w} R_{0}}{R^{2}{ }_{0}-R^{2} w}\right)\left(r-R_{w}\right)\left(r-R_{0}\right) \\
& +P_{w} \frac{R_{w}^{2}}{r^{2}},
\end{aligned}
$$

$$
\begin{aligned}
& \sigma_{\theta(\text { Gas flow })}= a_{1}\left(1+\frac{R_{w}^{2}}{r^{2}}\right)-a_{2}\left(1+3 \frac{R_{w}^{4}}{r^{4}}\right) \cos 2 \theta \\
&-\tau_{x y}^{\circ}\left(1+3 \frac{R_{w}^{4}}{r^{4}}\right) \sin 2 \theta \\
&-2 \frac{\eta}{r^{2}}\left(P_{f_{0}}-P_{w}\right) \cdot R_{0} \cdot R_{w}\left[\frac{R_{0} R_{w}-r^{2}}{R_{0}^{2}-R_{w}^{2}}\right] \\
&-P_{w} \frac{R_{w}^{2}}{r^{2}}, \\
& \sigma_{z(\text { Gas flow })} \sigma_{z}^{\circ} \\
&-4 v \times\left(a_{2} \times \frac{R_{w}^{2}}{r^{2}} \times \cos 2 \theta+\tau_{x y}^{\circ} \times \frac{R_{w}^{2}}{r^{2}} \times \sin 2 \theta\right) \\
&+2 \eta\left(P_{f_{0}}-P_{w}\right)\left(\frac{R_{w} R_{0}}{R_{0}-R_{w}}\right)\left(\frac{1}{R_{0}}-\frac{1}{r}\right) \\
&+\frac{2 \eta v}{R_{0}+R_{w}}\left(P_{f_{0}}-P_{w}\right)\left(R_{w}\right) .
\end{aligned}
$$

In order to highlight the effect of non-Darcy assumption, the above equations are compared with the existing solutions based on Darcy assumption. Here, the comparison is performed with the Darcy model presented in [3]. The results show that the difference between stresses in Darcy and non-Darcy flow regimes is proportional to $\eta\left(P_{f 0}-P_{w}\right)$. This means that in reservoirs with high drawdown pressure $\left(P_{f 0}-P_{w}\right)$, the difference between Darcy and non-Darcy stresses is more significant.

\section{Numerical model}

In this section, the applicability of the above proposed analytical solutions is examined numerically. The data corresponding to a typical reservoir were assumed for this purpose as shown in Table 1.

Table 1. Reservoir characteristics for laminar and turbulent flows.

\begin{tabular}{ll}
\hline$\sigma_{v}$ & $57 \mathrm{MPa}$ \\
$\sigma_{H}=\sigma_{h}$ & $28.5 \mathrm{MPa}$ \\
$P_{w}$ & $5 \mathrm{MPa}$ \\
$P_{f 0}$ & $20 \mathrm{MPa}$ \\
$R_{0}$ & $1000 \mathrm{~m}$ \\
$R_{w}$ & $0.1 \mathrm{~m}$ \\
$\eta$ & 0.25 \\
$\vartheta$ & 0.46 \\
$\beta$ & 0.005 \\
$\rho$ & $2000 \mathrm{~kg} / \mathrm{m}^{3}$ \\
$Q_{0}$ & $570.5 \times 10^{3} \mathrm{~m}^{3} / \mathrm{s}$ \\
$h$ & $200 \mathrm{~m}$ \\
\hline
\end{tabular}


Abaqus software was used for numerical simulations. In numerical modeling three steps are followed: defining the geometry and the boundary conditions; assigning material characteristics as well as the loading conditions; and mesh generation and the model analysis. In this study, axisymmetric simulation of a vertical wellbore was carried out. The pore pressure at the top surface was set to zero, at the well bore wall was assumed to be $P_{w}$, and at distances far from the well was considered equal to the reservoir pressure $\left(P_{f 0}\right)$ across the production layer. The porous elastic material model was used in this simulation. At the bottom of the reservoir, displacements in the vertical directions were restrained and similarly the radial displacements at distances far from the well were restrained.

Finer mesh was used near the wellbore because of the rapid stress changes that are expected near the wellbore; and coarser mesh was used in the regions far from the wellbore.

Axisymmetric simulation was used in modeling with 78400 CAX8RP type (eight-node biquadratic displacement, bilinear pore pressure, reduce integration) elements as depicted in Figure 1. In addition, non-Darcy flow was modeled by adding the velocitydependent term to permeability and defining $\beta$ in Forchheimer equation [28].

Figures 2 to 5 show the pore pressure as well as radial, tangential, and vertical stresses corresponding

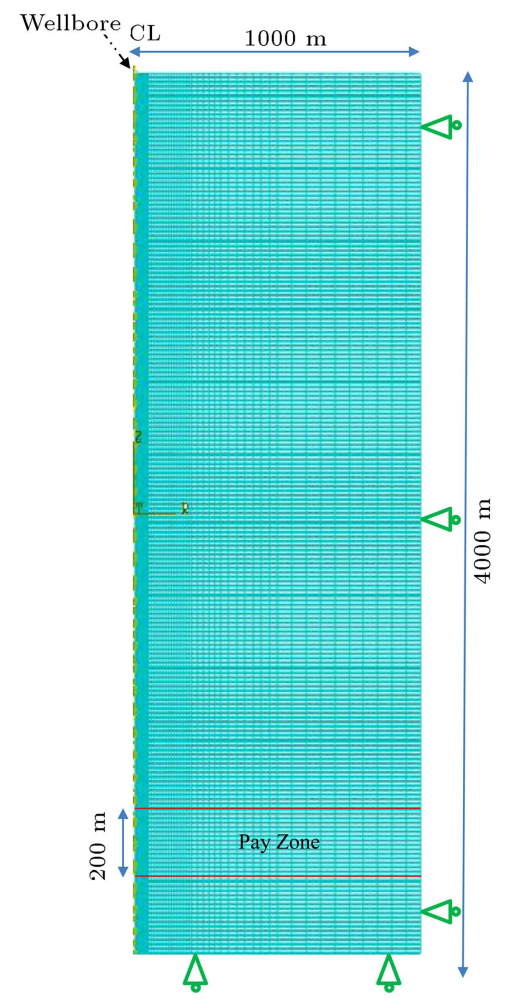

Figure 1. Axisymmetric mesh used for the model. to both Darcy and non-Darcy flows. In all figures, distance from the well is $5 R_{w}$ (i.e., $0.6 \mathrm{~m}$ in this model) away from the wellbore wall, where the disturbed zone due to drilling is expected to occur [29].

Figures 2 to 5 illustrate the results for analytical and numerical solutions in two regimes of Darcy and non-Darcy flows. As is observed, both analytical and numerical results have the same trend in the wellbore vicinity. The average difference between analytical and numerical results is less than $12.5 \%$ near the wellbore wall in all cases. The difference may result from estimation of elastic input parameters in the numerical simulation or variation of permeability with velocity in numerical modeling.

In Figure 2, the pore pressure at the wellbore wall is equal to $P_{w}$ and it approaches $P_{f 0}$ by moving the well away from the wellbore. The results indicate that the pore pressure calculated for non-Darcy Forchheimer flow (Eq. (4)) is $72 \%$ larger than that for the Darcy flow (Heidarian et al.) [30]. This number is $67 \%$ in numerical simulations, which is comparable with analytical results.

In the analytical solution presented by Fjar et al. (1992) [30] (Appendix A, Figure A.2), when $P_{f}$ is constant, the radial stress increases from $P_{w}$ to $\sigma_{H}$, which is similar to the trend observed in Figure 3. In addition, the results of Figure 3 show that each

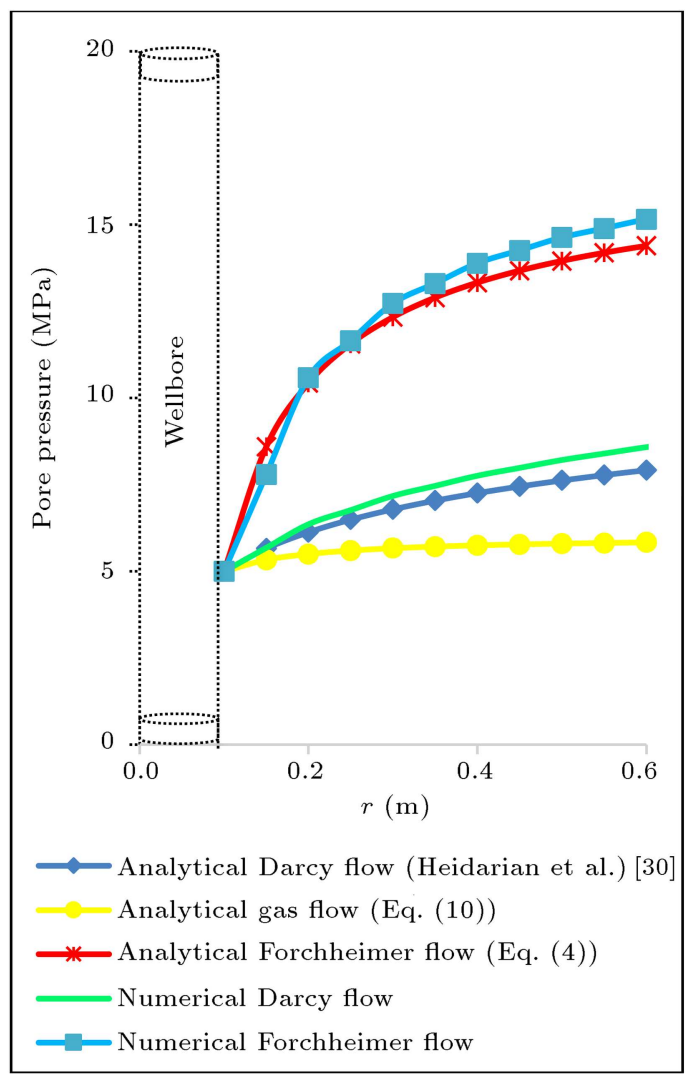

Figure 2. Pore pressure variation around the wellbore in Darcy and non-Darcy flow regimes. 


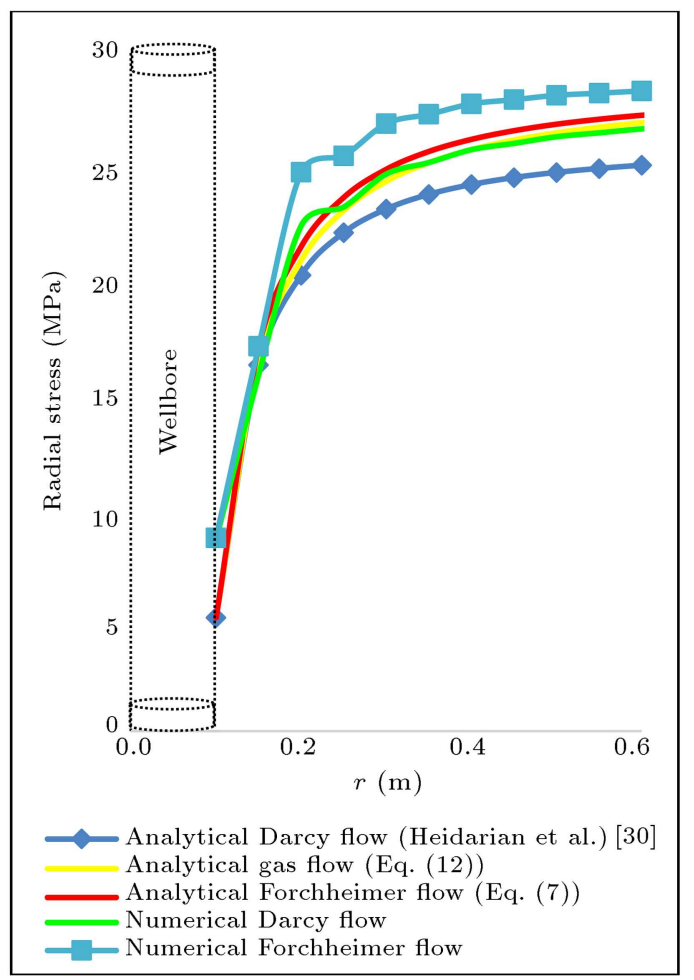

Figure 3. Radial stresses around the wellbore in Darcy and non-Darcy flow regimes.

average radial stress in non-Darcy Forchheimer flow regime (Eq. (7)) is $7.3 \%$ larger than the corresponding one in the Darcy flow regime. Correspondingly, the radial stress in non-Darcy flow is $7 \%$ larger than that in the Darcy flow according to the results of the numerical modeling. It should be mentioned that the amount of stress increase depends on the reservoir characteristics and it may vary from case to case.

Considering the analytical solutions of Fjar et al. (1992) [3], when $P_{f}$ is constant (see Appendix A, Figure A.2), the tangential stress around the wellbore is maximum; however, it decreases rapidly by moving away from the wellbore wall and reaches the in-situ stress, $\sigma_{H}$. Similar trend is observed in Figure 4 for the case of the current study. Here, the average tangential stress in the non-Darcy Forchheimer flow regime is $10.5 \%$ greater than that in the Darcy flow regime based on the results of analytical models. The results for nonDarcy flow in numerical simulations appear to be $0.16 \%$ larger than those for the Darcy flow.

In Figure 5, the average vertical stress obtained using the analytical approach in non-Darcy Forchheimer flow regime is $5 \%$ greater than that in the Darcy flow regime. The results of numerical simulations show $2.5 \%$ larger value for the vertical stress in non-Darcy flow than in the Darcy regime.

In interpreting the above results, it is important to note the two implicit assumptions that are embedded in the presented equations: (a) The flow is radial in

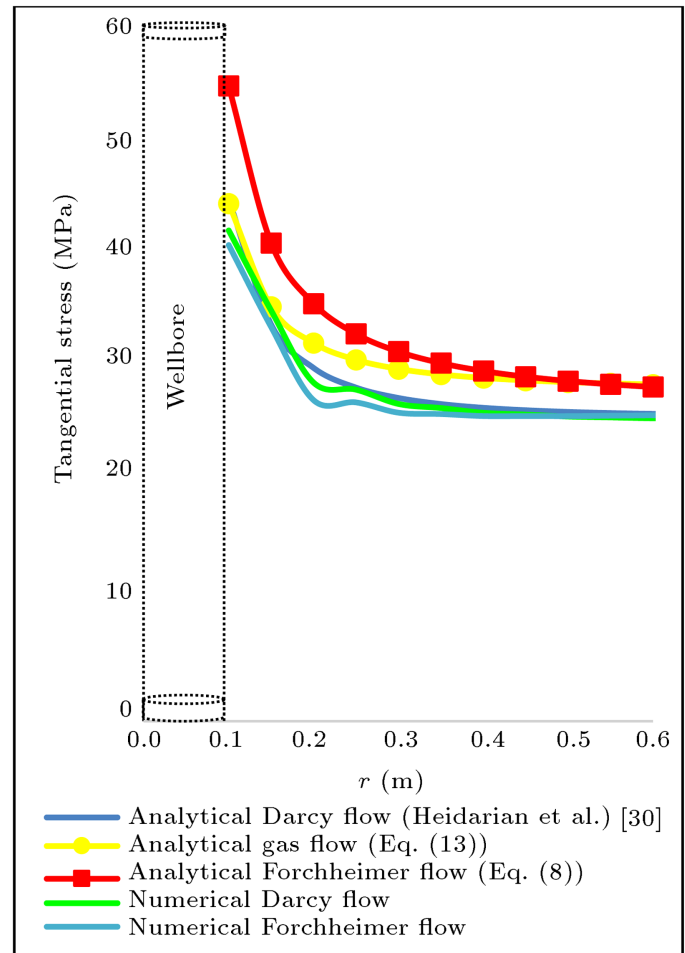

Figure 4. Tangential stresses around the wellbore in Darcy and non-Darcy flow regimes.

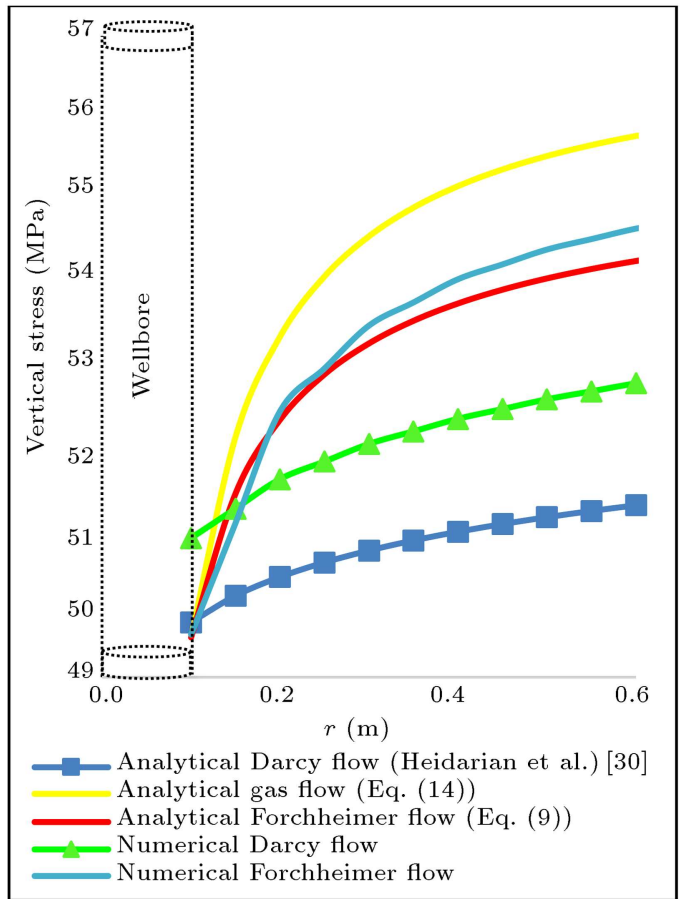

Figure 5. Vertical stresses around the wellbore in Darcy and non-Darcy flow regimes.

the wellbore and (b) The formation is homogeneous as considered in the developed equations in Appendix A. In addition, the sensitivity of the reservoir properties to the results needs to be investigated in the continuation of this work. 


\section{Sensitivity analysis of reservoir properties}

In this section, the sensitivity analysis of reservoir properties to induced stresses around a wellbore in nonDarcy flow regime is presented.

For this purpose, the effects of these parameters, including drawdown pressure, thickness of the pay zone, and drainage radius on induced stresses are investigated.

Parametric analysis is carried out according to Table 2 on analytical equations (Eq. (4) and Eqs. (7) to (10)) in the way that one parameter is changed and others are kept unchanged as in Table 1.

Figures 6 to 9 show the effect of drawdown pressure on radial, tangential, and vertical stresses.

As shown in the numerical values and Figure 6, the radial stresses near the wellbore in non-Darcy flow regime very slightly decrease with increasing drawdown pressure, which can be ignored in practical application.

Considering Figure 7, by increasing the drawdown pressure, the tangential stress near the wellbore increases. Also, according to Figure 8, the vertical stress decreases by increasing the draw-down pressure. This means that when draw down pressure increases, the tangential stress increases and vertical stress decreases, leading to more geomechanical problems like sand production.

Similar procedure to the above is applied to find out the effect of thickness of the pay zone $(h)$ on induced stresses around the wellbore. Thickness of the pay zone has a significant effect on radial stresses around a wellbore; by increasing the pay zone thickness from $5 \mathrm{~m}$ to $200 \mathrm{~m}$, radial stresses increase rapidly from negative to positive values. The effect of the pay zone thickness on radial stress is shown in Figure 9.

According to Figure 10, when thickness increases

Table 2. Parametric analysis of reservoir properties.

\begin{tabular}{cc}
\hline Parameter & Value \\
\hline Drawdown & $2 \mathrm{MPa}$ \\
pressure & $5 \mathrm{MPa}$ \\
$\left(P_{f 0}-P_{w}\right)$ & $10 \mathrm{MPa}$ \\
& $15 \mathrm{MPa}$ \\
& $5 \mathrm{~m}$ \\
Thickness of & $25 \mathrm{~m}$ \\
the pay zone & $50 \mathrm{~m}$ \\
$(h)$ & $200 \mathrm{~m}$ \\
& \\
Drainage & $250 \mathrm{~m}$ \\
radius & $500 \mathrm{~m}$ \\
$\left(R_{0}\right)$ & $750 \mathrm{~m}$ \\
& $1000 \mathrm{~m}$ \\
\hline
\end{tabular}

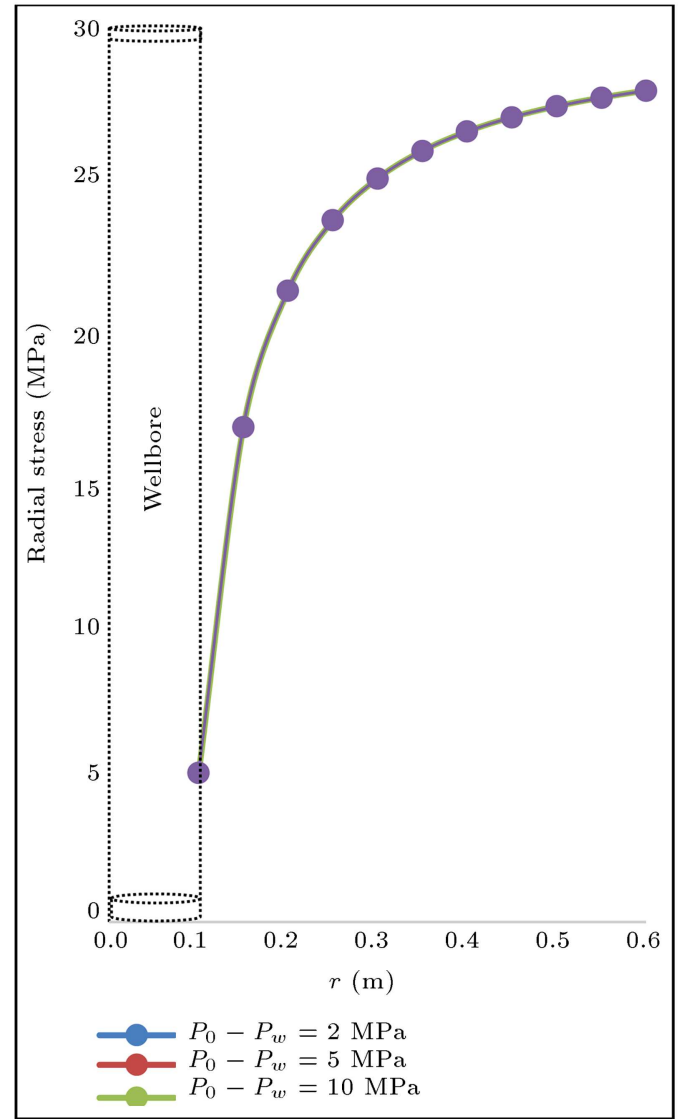

Figure 6. The effect of draw down pressure on radial stresses in non-Darcy flow regime.

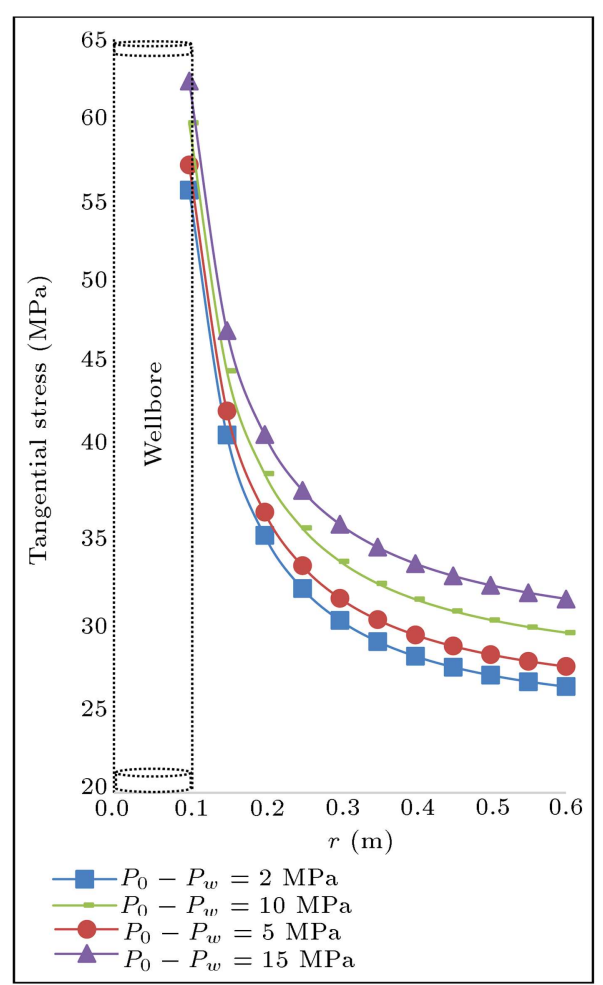

Figure 7. The effect of draw down pressure on tangential stresses in non-Darcy flow regime. 


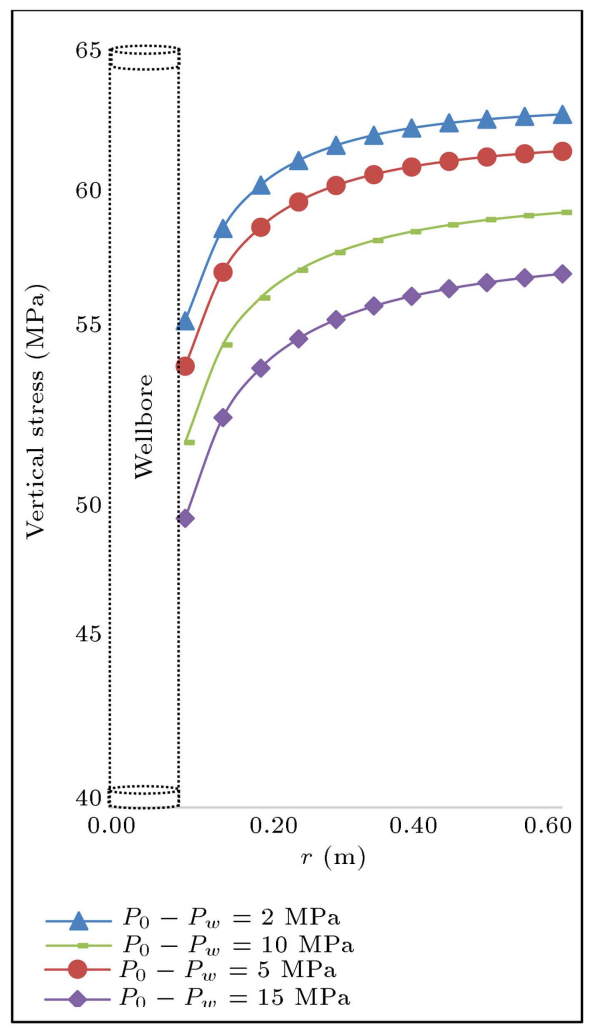

Figure 8. The effect of draw down pressure on vertical stresses in non-Darcy flow regime.

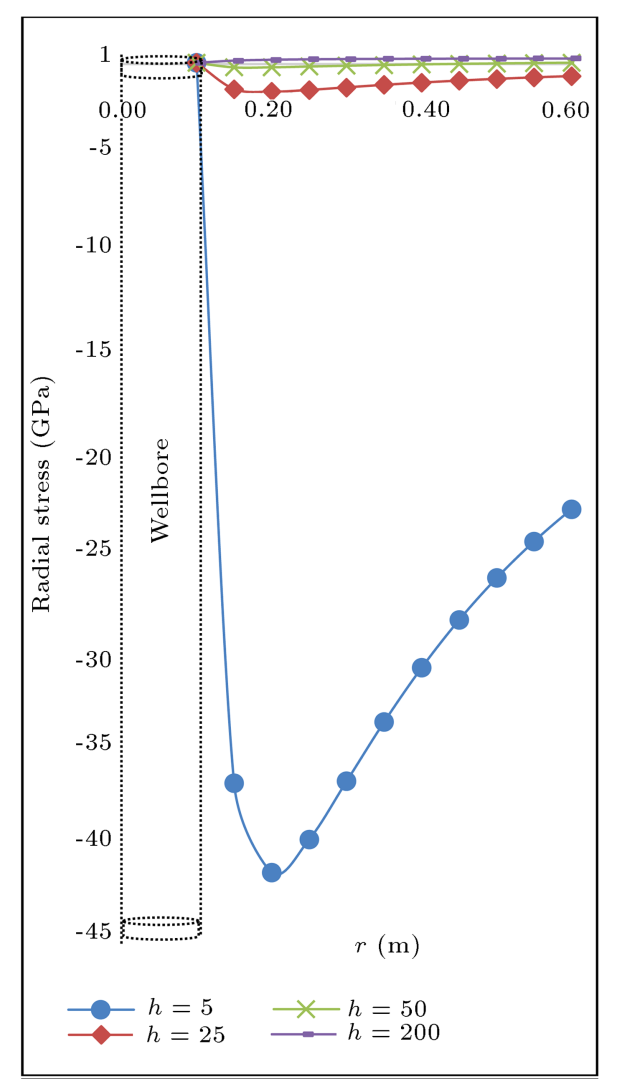

Figure 9. The effect of pay zone thickness on radial stresses in non-Darcy flow regime.

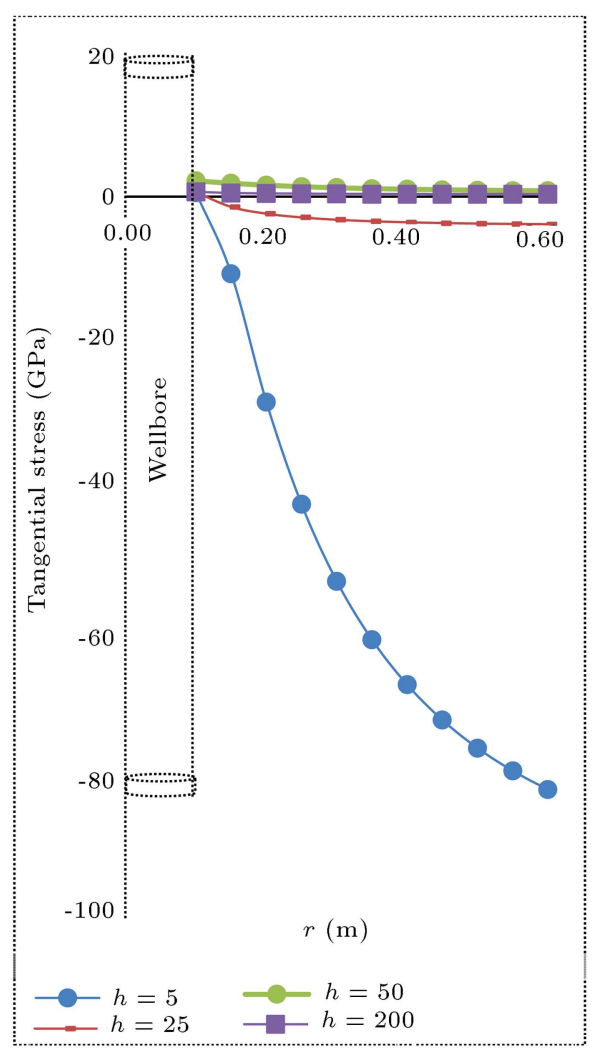

Figure 10. The effect of pay zone thickness on tangential stresses in non-Darcy flow regime.

from $5 \mathrm{~m}$ to $50 \mathrm{~m}$, the tangential stress increases rapidly and then decreases.

In Figure 11, unlike the horizontal stresses, by increasing the pay zone thickness, the vertical stress decreases; thus, the potential of mechanical failure increases dominantly in a thin pay zone.

The drainage radius on stresses around a bore hole has a minor effect. By increasing the drainage radius, horizontal stresses (radial and tangential) increase and vertical stress decreases. However, tangential stress is more sensitive to the change of drainage radius than to the changes of radial and vertical stresses.

\section{Conclusions}

According to the results of this study, Darcy flow assumption was not appropriate to gas reservoir and situations like hydraulic fracture; therefore, two sets of stress equations were developed that would be useful to geomechanical problems, e.g., wellbore stability, sand production, and completion design, with the non-Darcy fluid flow assumption.

Analytical solutions were developed and compared with the numerical modelling for a typical reservoir and the changes in pore pressure, as well as radial, tangential, and vertical stresses in non-Darcy flow regime were investigated. 


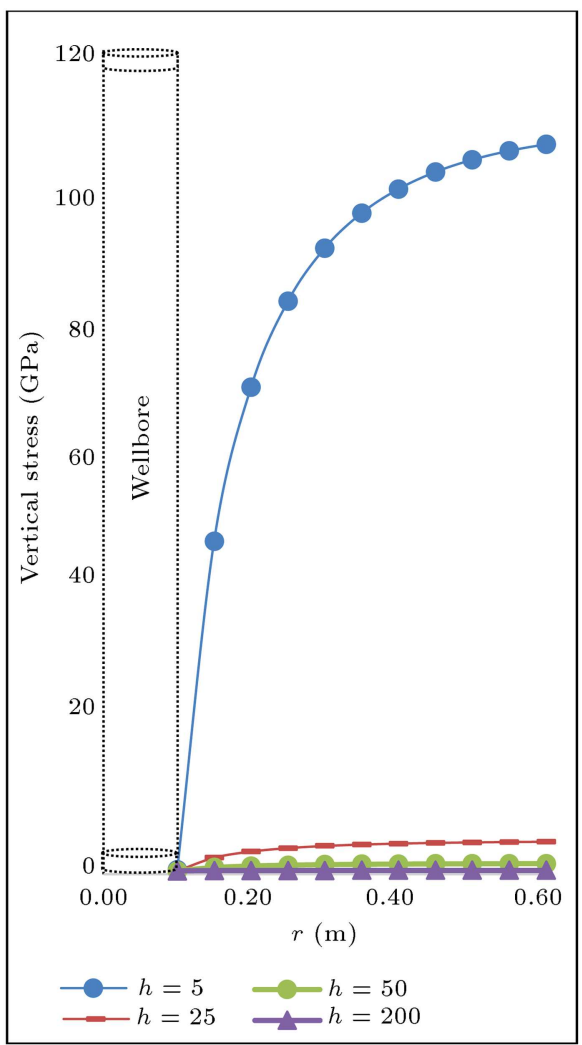

Figure 11. The effect of pay zone thickness on vertical stresses in non-Darcy flow regime.

The results indicated that the pore pressure and stresses in non-Darcy flow regime had greater values than those in the Darcy flow regime, where the difference was a function of several parameters including the drawdown pressure.

From the presented results of this work, it is concluded that using Darcy flow assumption for stress calculations near wellbore for gas wells may result in significant error, giving incorrect stress data for design purposes including wellbore stability analysis. On the other side, for example, the induced stresses extracted from Eqs. (7) to (14) and compared with appropriate failure criteria can be used in wellbore stability analysis.

Also, the sensitivity analysis of reservoir properties to induced stresses around a well bore in non-Darcy flow regime was carried out and it was concluded that the thickness of the pay zone had a more significant effect on induced stresses than draw down pressure and drainage radius.

\section{References}

1. Kang, Y., Yu, M., Miska, S.S.Z., Takach, N., et al. "Wellbore stability: A critical review and introduction to DEM", SPE Annu. Tech. Conf. Exhib., no. October, pp. 4-7 (2009).
2. Acock, A., ORuarke, T., Shirmboh, D., et al. "Practical approaches to sand management", Oil F. Rev., 16(1), pp. 10-27 (2004).

3. Fjaer, E., Holt, R.M., Raaen, A.M., Risnes, R., and Horsrud, P., Petroleum Related Rock Mechanics, 53, Elsevier (2008).

4. Risnes, R., Bratli, R.K., Horsrud, P., et al. "Sand stresses around a wellbore", Soc. Pet. Eng. J., 22(6), pp. 883-898 (1982).

5. Agheshlui, H. and Matthai, S.K. "The impact of layering and heterogeneity on stresses around boreholes", in ECMOR XIV-15th European Conference on the Mathematics of Oil Recovery (2016).

6. Ong, S., Atlas, B., Ramos, R., Exploration, A., Technology, P., and Zheng, Z. "Sand production prediction in high rate, perforated and open-hole gas wells", Production (2000).

7. Han, G. and Dusseault, M.B. "Description of fluid flow around a wellbore with stress-dependent porosity and permeability", J. Pet. Sci. Eng., 40(1-2), pp. 1-16 (2003).

8. Chen, G., Jin, Y., Li, L., and Zhou, B. "Analysis of vertical well collapse volume in radial porous media flows of a high pressure gas", In 50th US Rock Mechanics/Geomechanics Symposium (2016).

9. Hassani, A.H., Veyskarami, M., Al-ajmi, A.M., and Masihi, M. "Rock mechanics \& mining sciences. A modified method for predicting the stresses around producing boreholes in an isotropic in-situ stress field", Int. J. Rock Mech. Min. Sci., 96, October 2016, pp. 85-93 (2017).

10. Li, D. and Engler, T.W. "Literature review on correlations of the non-Darcy coefficient", SPE Permian Basin Oil Gas Recover. Conf., no. 2, pp. 1-8 (2013). http://www.onepetro.org/doi/10.2118/70015-MS.

11. Al-Hussainy, R., Ramey Jr, H.J., Crawford, P.B., et al. "The flow of real gases through porous media", $J$. Pet. Technol., 18(5), pp. 624-636 (1966).

12. Wang, J.G., Kabir, A., Liu, J., and Chen, Z. "Effects of non-Darcy flow on the performance of coal seam gas wells", Int. J. Coal Geol., 93, pp. 62-74 (2012).

13. Miskimins, J.L., Lopez, H.D.J., Barree, R.D., et al. "Non-Darcy flow in hydraulic fractures: does it really matter?", in SPE Annual Technical Conference and Exhibition (2005).

14. Detournay, E. and Cheng, A.D. "Poroelastic response of a borehole in a non-hydrostatic stress field", Int. J. Rock Mech. Min. Sci. Geomech. Abstr., 25(3), pp. 171-182 (1988).

15. Amao, A.M. "Mathematical model for Darcy Forchheimer flow with applications to well performance analysis", PhD Thesis, Texas Tech University (2007). 
16. Kundu, P., Kumar, V., and Mishra, I.M. "Experimental and numerical investigation of fluid flow hydrodynamics in porous media: Characterization of Darcy and non-Darcy flow regimes", Powder Technol, 303, pp. 278-291 (2016).

17. Cheng, A.H.-D., Detournay, E., and Abousleiman, Y., Poroelasticity, 27, Springer (2016).

18. Timoshenko, S.P. and Gere, J.M. "Theory of elastic stability", Courier Corporation (2009).

19. Bradley, W.B. "Failure of inclined boreholes", $J$. Energy Resour. Technol., 101(4), p. 232 (1979).

20. Fairhurst, C. "Methods of determining in-situ rock stresses at great depths: Tech", Rep. TRI-68, Mo. River Div. Corps Eng., Omaha, Nebr (1968).

21. Santarelli, F.J., Brown, E.T., and Maury, V. "Analysis of borehole stresses using pressure-dependent, linear elasticity", in International Journal of Rock Mechanics and Mining Sciences \& Geomechanics Abstracts, 23(6), pp. 445-449 (1986).

22. Li, P., Wang, K., and Lu, D. "Analytical solution of plane-strain poroelasticity due to surface loading within a finite rectangular domain", Int. J. Geomech., 17(4), p. 4016089 (2016).

23. Olson, J.E. and Srinivasan, S. "The impact of shale properties on wellbore stability", PhD Thesis (2005).

24. Wang, Z., Peden, J.M., and Damasena, E.S.H., et al. "The prediction of operating conditions to constrain sand production from a gas well", in SPE Production Operations Symposium (1991).

25. Ong, S.H., Ramos, G.G., and Zheng, Z. "Method of predicting the on-set of formation solid production in high-rate perforated and open hole gas wells", Google Patents (2007).

26. Irmay, S. "On the theoretical derivation of Darcy and Forchheimer formulas", Eos, Trans. Am. Geophys. Union, 39(4), pp. 702-707 (1958).

27. Al-Attar, H. and Al-Zuhair, S. "A general approach for deliverability calculations of gas wells", J. Pet. Sci. Eng., 67(3-4), pp. 97-104 (2009).

28. Systémes, D. "Abaqus analysis users manual", Simulia Corp. Provid. RI, USA (2007).

29. Zamanipour, Z., Miska, S.Z., Hariharan, P.R., et al. "Effect of transient surge pressure on stress distribution around directional wellbores", in IADC/SPE Drilling Conference and Exhibition (2016).

30. Heidarian, M., Jalalifar, H., Schaffie, M., Jafari, S., et al. "New analytical model for predicting the unstable zone around the borehole", SPE J., 19(6), pp. 1-177 (2014).
31. Al-Shaaibi, S.K., Al-Ajmi, A.M., and Al-Wahaibi, Y. "Three dimensional modeling for predicting sand production", J. Pet. Sci. Eng., 109, pp. 348-363 (2013).

\section{Appendix A}

Drilling induced stresses around a deviated wellbore in a homogenous medium subjected to anisotropic horizontal stresses are determined as [3]:

$$
\begin{aligned}
& \sigma_{r}=a_{1}\left(1-\frac{R_{w}^{2}}{r^{2}}\right) \\
& +a_{2}\left(1+3 \frac{R_{w}^{4}}{r^{4}}-4 \frac{R_{w}^{2}}{r^{2}}\right) \cos 2 \theta \\
& +\tau_{x y}^{\circ}\left(1+3 \frac{R_{w}^{4}}{r^{4}}-4 \frac{R_{w}^{2}}{r^{2}}\right) \sin 2 \theta \\
& +\frac{2 \eta}{r^{2}}\left(\begin{array}{c}
\int_{R_{w}}^{r} r^{\prime} \Delta P_{f}\left(r^{\prime}\right) d r^{\prime} \\
\\
\quad-\frac{r^{2}-R_{w}^{2}}{R_{0}^{2}-R_{w}^{2}} \int_{R_{w}}^{R_{0}} r^{\prime} \Delta P_{f}\left(r^{\prime}\right) d r^{\prime}
\end{array}\right) \\
& +P_{w} \frac{R_{w}^{2}}{r^{2}} \\
& \sigma_{\theta}=a_{1}\left(1+\frac{R_{w}^{2}}{r^{2}}\right) \\
& -a_{2}\left(1+3 \frac{R_{w}^{4}}{r^{4}}\right) \cos 2 \theta \\
& -\tau_{x y}^{\circ}\left(1+3 \frac{R_{w}^{4}}{r^{4}}\right) \sin 2 \theta \\
& -\frac{2 \eta}{r^{2}}\left(\begin{array}{c}
\int_{R_{w}}^{r} r^{\prime} \Delta P_{f}\left(r^{\prime}\right) d r^{\prime}-r^{2} \Delta P_{f}(r) \\
+\frac{r^{2}+R_{w}^{2}}{R_{0}^{2}-R_{w}^{2}} \int_{R_{w}}^{R_{0}} r^{\prime} \Delta P_{f}\left(r^{\prime}\right) d r^{\prime}
\end{array}\right) \\
& -P_{w} \frac{R_{w}^{2}}{r^{2}} \\
& \sigma_{z}=\sigma_{z}^{\circ} \\
& -4 \nu\left(a_{2} \frac{R_{w}^{2}}{r^{2}} \cos 2 \theta+\tau_{x y}^{\circ} \frac{R_{w}^{2}}{r^{2}} \sin 2 \theta\right) \\
& +2 \eta \Delta P_{f}(r) \\
& -4 \eta \frac{\nu}{R_{0}^{2}-R_{w}^{2}} \int_{R_{w}}^{R_{0}} r^{\prime} \Delta P_{f}\left(r^{\prime}\right) d r^{\prime} .
\end{aligned}
$$


In Eqs. (A.1) to (A.3):

$$
\begin{aligned}
& a_{1}=\left(\frac{\sigma_{x}^{\circ}+\sigma_{y}^{\circ}}{2}\right), \\
& a_{2}=\left(\frac{\sigma_{x}^{\circ}-\sigma_{y}^{\circ}}{2}\right), \\
& \eta=\frac{1-2 v}{2(1-v)} \alpha, \\
& \Delta P_{f}(r)=P_{f}(r)-P_{f_{0}}, \\
& \sigma_{x}^{\circ}=I_{x x^{\prime}}^{2} \sigma_{H}+I_{x y^{\prime}}^{2} \sigma_{h}+I_{x z^{\prime}}^{2} \sigma_{v}, \\
& \sigma_{y}^{\circ}=I_{y x^{\prime}}^{2} \sigma_{H}+I_{y y^{\prime}}^{2} \sigma_{h}+I_{y z^{\prime}}^{2} \sigma_{v}, \\
& \sigma_{z}^{\circ}=I_{z x^{\prime}}^{2} \sigma_{H}+I_{z y^{\prime}}^{2} \sigma_{h}+I_{z z^{\prime}}^{2} \sigma_{v}, \\
& \tau_{x y}^{\circ}=I_{x x^{\prime}} I_{y x^{\prime}} \sigma_{H}+I_{x y^{\prime}} I_{y y^{\prime}} \times \sigma_{h}+I_{x z^{\prime}} I_{y z^{\prime}} \sigma_{v},
\end{aligned}
$$

where:

$$
\begin{aligned}
& I_{x x^{\prime}}=\cos a \times \cos i \\
& I_{y x^{\prime}}=-\sin a, \\
& I_{z x^{\prime}}=\cos a \times \sin i, \\
& I_{x y^{\prime}}=\sin a \times \cos i, \\
& I_{y y^{\prime}}=\cos a, \\
& I_{z y^{\prime}}=\sin a \times \sin i \\
& I_{x z^{\prime}}=-\sin i, \\
& I_{y z^{\prime}}=0, \\
& I_{z z^{\prime}}=\cos i .
\end{aligned}
$$

In Eqs. (A.1) and (A.2), $\sigma_{H}$ and $\sigma_{h}$ are the maximum and minimum horizontal stresses, $R_{w}$ is the radius of the wellbore, $R_{0}$ is the drainage radius, $P_{f}$ is the pore pressure in the distance $r$ from the wellbore center, $P_{f 0}$ is the reservoir pressure, $v$ is Poisson's ratio or the formation, and $a$ is Biot coefficient. As depicted In Figure A.1, the angles $a$ and $i$ are used for transformation of stresses from a vertical to a deviated wellbore [30].

For solving Eqs. (A.1) to (A.3) simplified assumptions have been made by researchers; the graphical presentation of Eqs. (A.1) to (A.3), when $\frac{\partial p}{\partial r}=0$, is shown in Figure A.2 [3].

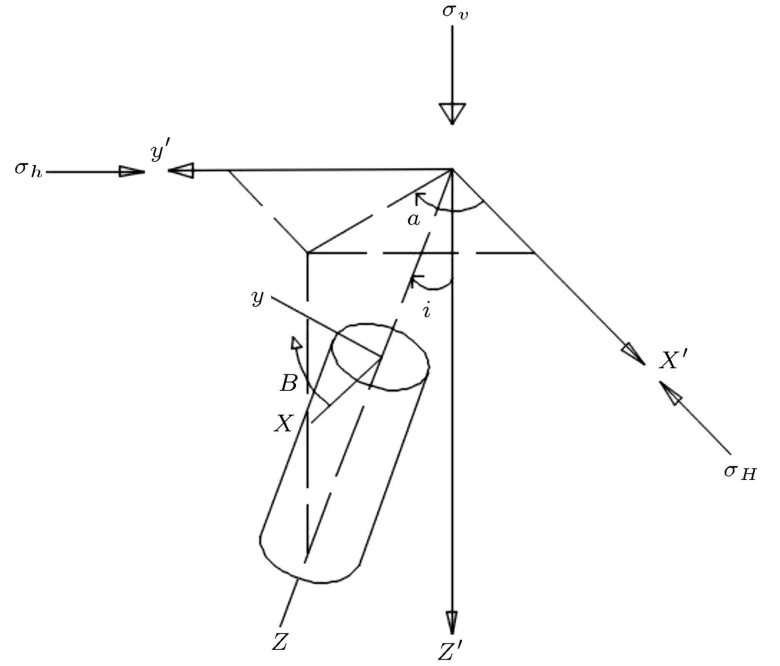

Figure A.1. Angles $a$ and $i$ are used for transformation of stresses from a vertical to a deviated wellbore [31].

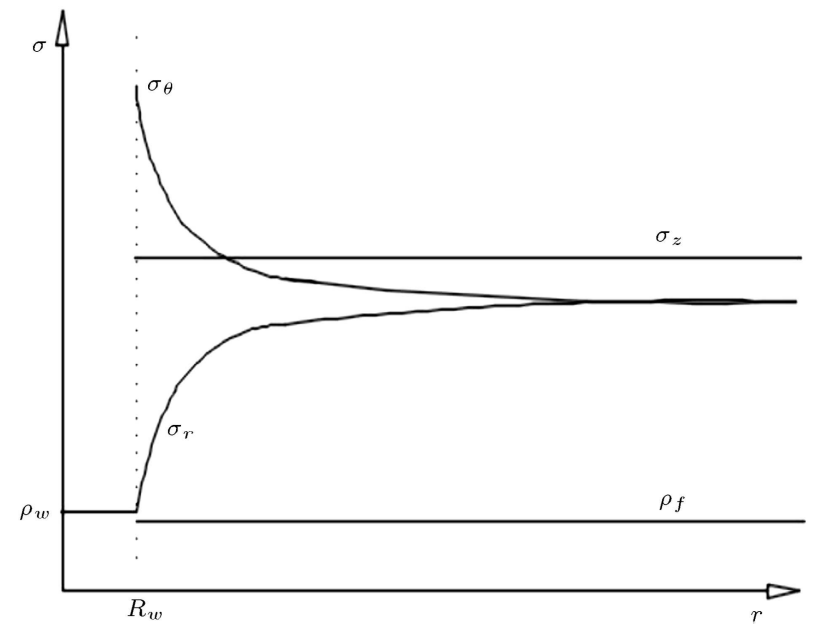

Figure A.2. Analytical solution to Eq. (A.1) for constant $P_{f}$ (elastic stress solution).

\section{Biographies}

Amin Tohidi is a $\mathrm{PhD}$ candidate at Amirkabir Universityof Technology. He received BS and MS degrees from the Civil and Environmental Department of Sharif University of Technology. His research interest is the petroleum-related rock mechanics.

Ahmad Fahimifar is a Professor in the Department of Civil and Environmental Engineering at Amirkabir University of Technology. He is also Head of Enhanced Oil Recovery Institute of Amirkabir University of Technology. His research interest is in the fields related to rock mechanics.

Vamegh Rasouli is the Chair and distinguished Professor in continental resources in the Department of Petroleum Engineering at University of North Dakota, 
USA. He has been a consulting engineer to Schlumberger in the past and is now serving as an instructor for their NExT (Network of Excellence in Training) program, delivering industry short courses worldwide in different subjects including petroleum geomechanics, drilling engineering, hydraulic fracturing, pore pressure estimation, and sand control. His research interest is in geomechanics and drilling. 